\title{
Reflexiones en torno al uso del motivo de Iliupersis en la narración titoliviana de la caída de Veyos
}

Reflections on the Use of the Iliupersis Motive in Livy's Narrative of the Fall of Veii

\author{
Agustín Moreno \\ CIECS-CONICET-UNC \\ agustinmoreno2003@yahoo.com.ar
}

\begin{abstract}
RESUMEN: El trabajo pretende contribuir al estudio de la alusión explícita al paralelo de la caída de Troya con la caída de Veyos en la narración titoliviana. Con el fin de complejizar el análisis de la cuestión, que últimamente ha sido pensado, principalmente, en un marco literario, la propuesta aquí es considerar, además de lo anterior, datos que exceden dicho marco, para lograr una comprensión más completa de las razones por las que Tito Livio juega con ese paralelo en este episodio.
\end{abstract}

ABSTRACT: The paper pretends to contribute to the study of the explicit allusion to the parallel of the fall of Troy with the fall of Veii in Livy's narrative. With the goal of making the analysis of the issue more complex, which lately has been thought, mainly, in a literary framework, the proposal here is to consider, besides the previous approach, information that surpasses the aforesaid framework, so as to achieve a more complex understanding of the reasons why Livy uses the referred parallel in this episode.

Palabras Clave: Tito Livio; veyentes; etruscos; troyanos; Iliupersis.

KEYwORDS: Livy; Veientes; Etruscans; Trojans; Iliupersis.

RECIBIDO: 27 de diciembre de 2016 • ACEPTADO: 29 de junio de 2017.

DOI: 10.19130/iifl.nt.2017.35.1.757

\section{Introducción}

Great victories have, however, a habit of becoming legends ${ }^{1}$

La identificación explícita del asedio de Veyos con el de Troya aparece dos veces en el libro 5 de Historia de Roma desde su fundación. La primera mención es colocada en boca de Ap. Claudio. Éste la emplea como un parangón en su argumentación para justificar el mantenimiento del asedio de la ciudad etrusca durante todo el año frente a la oposición de

${ }^{1}$ Cf. Ogilvie 1970, p. 628. 
los tribunos de la plebe. ${ }^{2}$ La segunda mención la leemos durante el resumen que sigue a la ocupación de Veyos, donde la idea es retomada por la persona del narrador. Allí, se subraya que la guerra, tal como la de griegos y troyanos, duró de hecho diez años. ${ }^{3}$

A partir de estas menciones explícitas, autores modernos han identificado otras posibles alusiones a la guerra entre griegos y troyanos im-

${ }^{2}$ Liv. 5.4.11-12: "Decem quondam annos urbs oppugnata est unam mulierem ab universa Graecia, quam procul ab domo! Quot terras, quot maria distans! Nos intra vicesimum lapidem, in conspectu prope urbis nostrae, annuam oppugnationem perferre piget. Scilicet quia levis causa belli est nec satis quicquam iusti doloris est quod nos ad perseverandum stimulet?" ("En una ocasión una ciudad fue atacada durante diez años por Grecia entera a causa de una sola mujer, y ¡qué lejos de casa!, ¡cuántas tierras, cuántos mares de por medio! Nosotros tenemos dificultad en mantener, a menos de veinte millas, casi a la vista de nuestra ciudad, un año de asedio"). Las traducciones citadas del texto de Tito Livio en este trabajo son las de Villar Vidal. Para la posición de los tribunos de la plebe, cf. 5.4.1-12; para el discurso completo de Ap. Claudio, cf. 5.3-6.

3 5.22.8: "Hic Veiorum occasus fuit, urbis opulentissimae Etrusci nominis, magnitudinem suam vel ultima clade indicantis, quod decem aestates hiemesque continuas circumsessa cum plus aliquanto cladium intulisset quam accepisset, postremo, iam fato quoque urgente, operibus tamen, non vi expugnata est” (“Así fue la caída de Veyos, la ciudad más opulenta de la nación etrusca, que dio muestras de su grandeza incluso en el desastre final, puesto que, sitiada ininterrumpidamente a lo largo de diez veranos y diez inviernos, después de haber infligido bastantes más reveses de los que había sufrido, al fin, ya bajo la presión del propio destino incluso, fue tomada, sin embargo, no al asalto, sino con obras de asedio"). Ogilvie señala en diferentes pasajes de su comentario ciertos puntos en la narración de Tito Livio donde se han debido ajustar determinados datos para concordar con la idea de los diez años, lo que se suele oponer con la noticia de Diodoro Sículo, quien afirma que fueron once años (14.93.2). Así, sobre la tregua por 20 años entre veyentes y romanos que Tito Livio menciona en 4.35.2: "the truce expires in 58.1 (tempus exierat) after only eighteen years have elapsed. It is likely that the expiry-date was pushed back to allow the necessary preliminaries before the Siege of Veii which convention demanded should last ten years as the Roman Siege of Troy, whereas tradition knew of only eight at the most" (Ogilvie 1970, p. 589). Más adelante leemos sobre los primeros tres años de la guerra: "Nothing happens in the first three years of the war in L.'s account $(4.60 .9,61.2-3,9)$. The first memorable event of any kind takes place in 403, and it might reasonably be held that 403 (399 on the absolute chronology) marked the true beginning of the war. Its start and in turn the expiry of the twenty years' truce were pushed back to increase the parallelism between Veii and Troy" (1970, p. 629). Cf. también Ogilvie 1970, pp. 628, 637, 647, 651. Asimismo, Ogilvie 1970, p. 637, destaca que la asociación de una guerra importante con la de Troya, tal como la leemos en el discurso de Ap. Claudio (5.4.11), había sido realizada ya por Demóstenes en su Discurso fúnebre (60.10). Kraus hace constar, sobre la lógica del discurso de Ap. Claudio, la opinión de uno de los evaluadores de su artículo para $T A P h A$, que sugiere que la misma derivaría de Tucídides (1.11). 
plícitas en la narración titoliviana. Algunos investigadores ponen énfasis en el motivo literario de dichas alusiones y se ha tendido a minimizar la importancia de otra razón externa a la literatura. Dentro de este grupo se encuentra el último trabajo que se detuvo en la cuestión, " "No second Troy': Topoi and refoundation in Livy, Book V", un artículo publicado por C. S. Kraus en 1994. Ahora bien, aunque la autora defiende esta postura, de todos modos desliza en una de sus notas al pie de página la posibilidad de que también podría existir una causa mítico-histórica detrás de la asociación entre Veyos y Troya, aspecto en el que no se detiene y que, a nuestro juicio, amerita una revisión.

Retomando estas dos cuestiones, nuestro texto se detendrá, en una primera instancia, en resumir las alusiones sugeridas por los diferentes investigadores y, en una segunda instancia, a partir de la referencia que ofrece en su artículo C. S. Kraus, ahondará en las posibles conexiones entre etruscos, especialmente veyentes, y troyanos fuera de la obra de Tito Livio, considerando no sólo otras fuentes literarias, sino también fuentes epigráficas y arqueológicas.

\section{Romanos como griegos y veyentes como troyanos}

Como señalamos en la introducción, algunos estudiosos modernos han ido más allá de las referencias explícitas y han sugerido que en el texto se pueden advertir en otros pasajes más alusiones al tema de la guerra de Troya, que refuerzan la caracterización de los romanos como griegos y de los veyentes como troyanos. ${ }^{4}$

Así, en los reclamos de los tribunos de la plebe que se oponen al planteo de Ap. Claudio al comienzo del libro V, los sufrimientos que aquéllos alegan que deben soportar las tropas romanas en el asedio de la ciudad etrusca, incluso durante el invierno, por decisión de los tribunos

${ }^{4}$ Hubaux 1958, p. 199, afirma que el primero en señalar esta analogía habría sido Niebuhr (cf. Niebuhr 1832,pp. 472, 478). Una posición crítica frente a los "homerismos" presenta Bayet 1964, pp. 125-134, esp. 133-134, en un apéndice al libro 5 de Tito Livio. Allí, el estudioso francés defiende que el relato de la toma de Veyos presenta una mezcla de información latina, griega y etrusca, a la que realza, y resta importancia a esos "homerismos", que habrían sido obra de un poeta helenizante anterior a Tito Livio, quizá Ennio. Leemos una crítica a Bayet en Hubaux 1958, pp. 199-201. 
militares evocan los relatos de los griegos ante las murallas de Troya en el Agamenón de Esquilo y en el Ayax de Sófocles. ${ }^{5}$

También la toma de la ciudad etrusca está presentada de un modo similar a la de Troya. Se puede observar un paralelo entre Camilo y Odiseo en tanto que ambos dirigen los recursos militares y divinos hacia el enemigo. ${ }^{6}$ En ese marco, la imagen del túnel (cuniculus) que hace construir el dictador lleno de hombres a la espera de atacar, estaría modelada a partir del caballo de Troya. ${ }^{7}$ Asimismo, Kraus sugiere que la historia que trae a colación Tito Livio sobre soldados romanos saliendo del túnel y arrancando las entrañas de una víctima a los etruscos en pleno ritual religioso para llevárselas a Camilo, puesto que quien las sacrificara tendría asegurada la victoria, estaría basada en el robo del paladión por Odiseo y Diomedes. ${ }^{8}$

${ }^{5}$ Ogilvie 1970, p. 633, compara el pasaje 5.2.6 con A. Ag. 559 ss., mientras que Kraus 1994, p. 272, n. 22, vincula la referencia a la escarcha señalada en 5.2.7 con A. Ag. 335336 , y sobre la contraposición en la vida del soldado entre las miserias de la guerras y los placeres de la vida doméstica que leemos en 5.2.4, 6, 11-12, sugiere cf. S. Aj. 11991210 .

${ }^{6}$ Cf. Ogilvie 1970, pp. 673-674, y Ferri 2010, p. 66.

${ }^{7}$ Cf. 5.21.4-6, 10. Kraus juega con las acepciones del término cuniculus al establecer la relación entre el túnel en Veyos y el caballo de Troya: "A stratagem thus connected with religious rites, especially one involving a structure filled with soldiers, is obviously modeled on the Trojan horse; one is tempted to refer to this cuniculus as Camillus' Trojan rabbit" (1994, p. 272). Aspecto señalado anteriormente por Niebuhr 1832, p. 478, y Hubaux 1958, pp. 117, 222-223. Sin negar esta alusión, no deberíamos dejar de tener presente aquella información que da sentido a lo que leemos dentro de un contexto etrusco o, si se quiere, explícitamente de enfrentamiento romano etrusco. Así, señala Ogilvie vinculando los túneles que se hicieron para la toma de Fidenas y de Veyos: "the recurrence of the story apropos of Fidenae indicates that there was a long-standing tradition that an Etruscan siege was once successfully ended by means of a cuniculus" (1970, p. 672). Cf. también sobre esta cuestión Gagé 1954, p. 62, n. 3, y Hubaux 1958, p. 117. Cabe recordar que los cuniculi son túneles de drenaje típicos en la zona de Veyos (cf. Bayet 1964, p. 132; Hubaux 1958, pp. 118-120; Ogilvie 1970, pp. 570, 628, 658-659; Cornell 1999, p. 359). Sobre la conexión con tamiz religioso entre el cuniculum de Veyos y el túnel por el que se debía canalizar el agua del lago Albano, cf. Hubaux 1958, pp. 121 ss.; Ogilvie 1970, p. 659, y Ferri 2010, pp. 73-74.

${ }^{8}$ Cf. 5.21.8-9, Kraus 1994, p. 272, quien se basa en Serv. ad A. 2.166. No comprendo la referencia de Kraus a Hubaux 1958, p. 117, en torno a esta alusión, la misma que advierte Kraus señala Ferri 2010, p. 74. Por su parte, el autor italiano también observa una estrecha relación entre el paladión y la estatua de Juno Reina en otra parte de su obra (2010, p. 66). 
Hasta aquí las alusiones sugeridas especialmente en torno a la identificación entre griegos y romanos, ${ }^{9}$ a continuación citaremos aquellos paralelos que tienen que ver con los sitiados. La caída de Veyos es descrita por Tito Livio en términos semejantes a los que se vinculan con los sucesos finales de Troya. El arúspice etrusco raptado por un guardia romano, conducido ante el senado, que vaticina la derrota de su patria y que expone cómo han de proceder los romanos ante el prodigio del lago Albano para obtener el favor de los dioses de Veyos, se correspondería con la captura de Heleno por Odiseo. ${ }^{10}$ Asimismo, la presentación de la caída de Veyos como inexorable, con los dioses abandonando la ciudad, la idea de que los adivinos ya la habían entregado y los sentimientos de los sitiados, también estaría modelada en el caso troyano. ${ }^{11}$ Incluso, entre los paralelos, C. S. Kraus menciona la referencia a la ciudad etrusca como opulentísima que, una vez más, nos recordaría el caso de la ciudad de Asia. ${ }^{12}$

Aunque algunas alusiones puedan parecer un tanto forzadas, no es nuestra intención aquí discernir cuáles pueden ser más acertadas, cuáles habría que descartar o de cuáles deberíamos desconfiar, pues, sean algu-

${ }^{9}$ Ferri 2010, p. 66 cita, asimismo, una sugerencia de Dumézil, quien ve alusiones a la guerra de Troya en "vari conflitti interni, sia tra «capi» che tra «ordini», prima del ricompattamento e dell'attacco finale”: Agamenón-Aquiles, Agamenón-Tersites, UlisesTersites, Camilo-Ap. Claudio, patricios-plebeyos.

${ }^{10}$ El pasaje de Tito Livio es 5.15.4-12, el de Heleno está en S. Phil. 604-614. Sobre el paralelo con el rapto de Heleno, cf. Gagé 1950, p. 76; Ruch 1966, pp. 344-346; Ogilvie 1970, p. 661, quien se lo atribuye a Parke, Kraus 1994, p. 272, y Ferri 2010, p. 66. Ya Gagé 1954, pp. 54-55, menciona el paralelo como algo conocido por los estudiosos modernos, pero no lo atribuye a ningún investigador en especial. Una lectura diferente, que analiza el pasaje enmarcándolo en un contexto cultural etrusco, ofrece Bayet 1964, p. 131. Por su parte, Hubaux 1958, pp. 172-179, sugiere una explicación en torno al rapto del arúspice a partir de los distintos relatos que ofrecen las fuentes antiguas y vincula su deserción con la de los dioses veyentes. Sobre la deserción de los dioses de Veyos (5.15.11), Ogilvie 1970, p. 663, cita la observación de le Bas que detecta un paralelo con el caso de Troya en Il.22.213 y Verg. A. 2.351-352.

${ }^{11}$ Cf. 5.21.5-7. Kraus 1994, p. 272, n. 28, sugiere el paralelo con E. Tro. 15-16 y Verg. A. 2.241-249. Este último señalado por Ogilvie 1970, p. 675, quien aconseja leer los dos pasajes a la par y sugiere que ambos autores tendrían presente a Ennio. Kraus propone que la frase fatum urgens que encontramos en Liv. 5.22.8 habría sido retomada en Verg. A. 2.653. Vale recordar que la Eneida es posterior a la primera década de la obra de Tito Livio, como afirma Oakley 2004, p. 110.

${ }^{12}$ Referencia a la riqueza de Veyos: 5.20.1, 21.17, 22.8. Para el caso troyano, Kraus 1994, p. 273, cita a E. Tro. 18-19, Verg. A. 2.763-766. 
nas o todas las válidas, ya vimos que el propio Tito Livio explícitamente traza el paralelo entre los dos sitios. ${ }^{13}$

De todos modos, dos casos de alusiones discutidas podemos mencionar a manera de ejemplo: una, citada y rechazada por J. Bayet, según la cual el ataque sorpresivo de los veyentes a las posiciones romanas al comienzo del libro 5 podría compararse con el ataque de Héctor al campamento aqueo. ${ }^{14}$ La otra es una sugerencia de R. M. Ogilvie en su Commentary. Tito Livio narra que, luego de sendas derrotas ante faliscos y capenates - y antes del ataque final a Veyos - , un rumor se expandió agrandando el desastre sufrido, lo que hizo temer no sólo a los romanos del campamento de Veyos, sino incluso a los que se encontraban en Roma, donde se produjo una situación caótica. Allí, el historiador romano dice que ante el pánico hubo corridas a las murallas y que las mujeres recitaron plegarias en los templos. R. M. Ogilvie ve en esta imagen una similitud con aquella de la Ilíada donde Héctor va a la batalla. ${ }^{15}$ Sin embargo, esta relación, que pondría, vale remarcar, a los romanos en el rol de troyanos, no es aceptada por todos los estudiosos. ${ }^{16}$

Cabe considerar un aspecto más en el marco de los motivos literarios. Al investigador, familiarizado con la vinculación entre Roma y Troya o

${ }^{13}$ De todos modos, es interesante en ese tipo de ejercicio tener en cuenta la advertencia de Levene: "Allusion, as has often been remarked, is frequently indeterminate to a greater or lesser degree. It is indeterminate because there is no precise limit to how similar a phrase or linguistic usage or parallel situation has to be in order to be seen as meaningfully evoking another phrase or usage or situation, nor to how recently a particular model has to have been evoked in order for that text to be foregrounded for future allusions. Classicists have the additional problem that many of the texts to which ancient writers might be alluding no longer survive; so one is often faced with doubts whether a passage with a rare feature that might be allusive is primarily alluding to another passage which shares some aspect of it, or whether both passages might be more closely dependent on a lost original. The distinction between alluding to another historical event may also be hard to pin down firmly in many cases" (2010, p. 99). Cf. también p. 111.

${ }^{14}$ Bayet considera que "Le rapport est bien vague" (1964, p. 134). La misma postura sostiene Hubaux 1958, pp. 200-201. Ninguno de los dos autores señala quién trazó este paralelo. El pasaje de Tito Livio es 5.7.1-3, el de la Ilíada es el canto 8, especialmente, quizás, desde el verso 170 en adelante.

15 Ogilvie 1970, p. 669: "The panic at Rome with the scenes of women on the walls and of public prayer are taken from the Iliad, as Hector goes out to battle". El pasaje de Tito Livio es 5.18.11-12 y el de la Ilíada, 22.37-92.

${ }^{16}$ Kraus 1994, p. 272, que atribuye la relación a Burck, se muestra dubitativa, mientras que Levene 1993, p. 182, n. 17, no está de acuerdo. 
entre ésta y Alba o, incluso, entre troyanos y paduanos - todo lo cual leemos en los primeros libros de la obra de Tito Livio-, pero desconocedor de los hallazgos arqueológicos en Etruria, ${ }^{17}$ puede llamarle la atención la asociación de Troya con Veyos. No obstante, si pensamos en lo que hace notar R. M. Ogilvie, y retoman G. Paul y C. S. Kraus, en cuanto a que el motivo literario de la Iliupersis se encuentra presente con algunas variaciones en casi todas las descripciones de toma de ciudades en la Historia de Roma desde su fundación, el caso de Veyos tendría su explicación, porque todos los atacantes serían presentados como griegos, mientras que todos los que defienden encarnarían el papel de troyanos, como acabamos de ver. ${ }^{18}$

Sin embargo, más allá de que el uso del tópos de urbs capta pueda ser reconocido en varios pasajes de la obra, lo que tiene de particular el ejemplo del sitio de la ciudad etrusca, vale repetirlo una vez más, es que Tito Livio nos invita explícitamente a leerlo teniendo en mente el sitio de Troya. En el enfrentamiento con Alba, la referencia del historiador romano a Troya no es explícita al tratar de su destrucción, ${ }^{19}$ sino en el enfrentamiento que culminará con los albanos derrotados y aceptando el dominio romano. ${ }^{20}$ Es decir, cuando Tito Livio quiere mostrar que la guerra entre ambas ciudades es una guerra civil, ${ }^{21}$ lo que, obviamente, no es el caso del episodio que trabajamos aquí.

${ }^{17}$ Si bien la afirmación puede llamar la atención, el caso, por ejemplo, de Kraus 1994 muestra que se conozca o no la información arqueológica, la misma es deliberadamente dejada de lado. Un ejemplo donde podemos apreciar la falta de diálogo entre dos disciplinas afines en el marco de los estudios clásicos es en la crítica de los historiadores de la religión a aquellos investigadores formados en letras que desconocen los avances realizados por los primeros en el campo de estudio, lo que da pie a lecturas anacrónicas de las fuentes. Cf. Phillips III 2007, pp. 25-26.

${ }^{18}$ Ogilvie 1970, p. 320: “Almost all L.'s accounts of captured cities are variations on the Ilioupersis theme". Citado con asentimiento por Paul 1982, p. 148. Cf. también Ogilvie 1970, pp. 120-121, 628, 629, 637, 647, 651, 661, 663, 669, 673-674, 675; Paul 1982, pp. 149, 151-153; Kraus 1994, pp. 271-273. Conviene recalcar que esta afirmación de Ogilvie está en contradicción con la alusión que acabamos de citar (Ogilvie 1970, p. 669) entre los hechos de Roma y los de Troya.

${ }^{19}$ Cf. 1.29.

${ }^{20}$ Cf. 1.22.1-26.1.

21 1.23.1: "Haec nuntiant domum Albani. Et bellum utrimque summa ope parabatur, civili simillimum bello, prope inter parentes natosque, Troianam utramque prolem, cum Lavinium ab Troia, ab Lavinio Alba, ab Albanorum stirpe regum oriundi Romani essent" 
No queremos negar aquí la asociación que el lector pueda tejer a través del motivo de la Iliupersis, pero nos interesa ver por qué Tito Livio refuerza esa idea y no deja la alusión implícita como en los demás pasajes. Una explicación posible podría guardar relación con el origen asiático, lidio específicamente, de los etruscos. Tesis expuesta por primera vez por Heródoto ${ }^{22}$ y que parece haber estado en boga entre los autores del período augústeo. ${ }^{23}$ La hipótesis es probable. Se ha observado que en el libro segundo los veyentes, específicamente entre los etruscos, podían ser identificados como persas en el enfrentamiento con los 306 Fabios, suerte de 300 espartanos romanos. ${ }^{24}$ Sin embargo, aunque esto podría ser un nexo en la vinculación que da fruto a esa representación de veyentes como troyanos, ${ }^{25}$ tal vez se pueda identificar otra causa más para ello.

("Llevan los albanos estas noticias a su país. Por ambos bandos se preparaba la guerra con la mayor intensidad, una guerra que tenía todas las características de guerra civil, casi entre padres e hijos: unos y otros eran de ascendencia troyana, al provenir de Troya Lavinio, de Lavinio Alba, y de la estirpe real Alba los romanos"). Cf. también 1.23.7 y 28.7. Cf. Phillips 1982, p. 1004.

${ }^{22} \mathrm{Cf}$. Hdt. 1.94. Es oportuno decir que un análisis del pasaje puede leerse en Briquel 2013, pp. 42-45.

${ }^{23}$ Cf. Verg. A. 8.479-481. Cf. asimismo el epítome de Trogo Pompeyo: Just. 20.1.7. Incluso, sigue teniendo preeminencia dicha versión poco más tarde, como queda atestiguado por Estrabón en su Geografía (5.2.2 C220), quien reproduce lo dicho por Heródoto (1.94), o por Tácito en sus Anales (4.55.3 con Giardina 2004, pp. 26-27). Igualmente, Séneca transmite la misma idea al afirmar que "Tuscos Asia sibi vindicat" (Cons. Helv. 7.2). Interesantes observaciones sobre la leyenda lidia en época romana, con anterioridad y posterioridad al período augústeo, se pueden encontrar en Briquel 1991, pp. 479-488, quien no cuenta a Tito Livio entre los autores que aceptan esta tesis. Cf. también Briquel 2013, p. 51, n. 17. La única voz discrepante del período de Tito Livio parece ser la de Dionisio de Halicarnaso (1.29-30), quien defiende que los etruscos son un pueblo autóctono y antiguo. Sobre esta tesis de Dionisio, cf. Briquel 1983, pp. 86, 79, y 2013, pp. 37-42; Musti 1970, pp. 7-20 y passim; Scuderi 1978, pp. 95-99; Hartog 1999, p. 237; Sordi 2008, p. 91. Tesis precedentes a autores de la época de Augusto podemos leer en D. H. 1.25-28 y Str. 5.2.4 C220-221. Sobre una visión etrusca de la autoctonía en período helenístico (IV-III a. C.), cf. Briquel 1986.

${ }^{24}$ Cf. 2.48.8-50.11 con Ogilvie 1970, pp. 359-360.

${ }^{25}$ En cuanto al uso de motivos de la guerra de Troya para representar los enfrentamientos griegos contra los persas, cf. Hall 1989, p. 102. 


\section{¿Lazos mítico-históricos entre Veyos y Troya?}

Il est toujours malaisé de discerner le moment où quelque chose naît, que ce soit la vie sur la terre, l'homme parmi les animaux, ou une langue, ou une religion, ou un peuple, ou une légende. ${ }^{26}$

En 1994, C. S. Kraus señaló de paso, en una nota al pie de su artículo " 'No second Troy': Topoi and refoundation in Livy, Book V", que en la relación de Veyos con Troya que traza Tito Livio, además de los motivos literarios, "there is a mythico-historical logic as well, since Veii may also have claimed Trojan ancestry". ${ }^{27}$ Sin embargo, la autora no se explaya en la cuestión y se limita a reenviar al lector al trabajo "Aeneas and the twins" que T. J. Cornell publicó en 1975. Allí, la tesis de que en Veyos Eneas pudo haber recibido culto como fundador es atribuida a A. Alföldi, ${ }^{28}$ quien la sugiere a partir de los hallazgos en Veyos de estatuillas votivas de Eneas. Cornell se muestra reticente a esta hipótesis, dado que las pruebas no son tan concluyentes como Alföldi afirma. ${ }^{29}$ Tampo-

${ }^{26}$ Cf. Perret 1976, p. 791.

${ }^{27}$ Cf. Kraus 1994, p. 273, n. 29. Si bien la autora cita en su artículo el libro de Hubaux 1958, no hace referencia a que el investigador belga ya había aseverado el origen troyano de Veyos allí: "Véies et Capoue, dans la mesure où on les donne pour fondées par les Troyens - et dans le cas de Capoue, cette origine est attestée par ce passage même des Punica - devraient être à peu près du même âge" (1958, p. 272). Hubaux no adujo ninguna fuente ni bibliografía al respecto y, en una reseña a la obra, la afirmación fue inmediatamente objetada por Adams 1959, p. 448.

${ }^{28}$ Las dos obras de Alföldi que se discuten son Die trojanischen Urahnen der Römer de 1957 y Early Rome and the Latins de 1965.

${ }^{29}$ Sobre las estatuillas asevera Alföldi: "They bear witness to the role of Aeneas as founder" (citado por Cornell 1975, p. 12, n. 4). Cornell 1975, p. 12, se muestra escéptico al respecto y sugiere que si Eneas fue excepcionalmente popular en Etruria, ello pudo haberse debido a que los etruscos pensaron que el héroe había ido a su patria. También cuestiona Cornell la idea de que haya una conexión entre la presencia de Eneas en Etruria y la noción de que los etruscos hayan venido de Asia Menor. Cf. Cornell 1999, p. 91. Con anterioridad a los trabajos de Alföldi, Gagé 1950, pp. 73-74, 94-96, y 1954, 55, sugiere la hipótesis del culto a Eneas en Veyos y la idea de que los troyanos se hubieran visto involucrados como fundadores de ésta y otras ciudades en Etruria. Asimismo, vincula la idea del parentesco troyano con migraciones de Asia Menor a Etruria. Antes de Cornell, Galinsky rechazaba la hipótesis de un culto a Eneas en Veyos basada en esas estatuillas votivas: "votive statuettes often do not represent the patron deity of a given sanctuary, and the ex-votos of Aeneas and Anchises therefore provide no indication that the cult at Veii centered around Aeneas. The votive inscriptions do not mention his name, while 
co, a su juicio, lo son las que el historiador austro-húngaro aduce para el caso de otras ciudades etruscas, como por ejemplo Vulci. ${ }^{30}$

Pero no es A. Alföldi el único en afirmar aquello. La hipótesis sobre la existencia de un culto o cultos a Eneas en una o más ciudades etruscas parece estar asociada a autores que sostienen que la leyenda del héroe troyano en Italia se formó en territorio etrusco antes de pasar al Lacio y a Roma. En esta línea también se inscribe el célebre libro de G. K.

dedications to Minerva and Ceres are prominent" (1969, p. 136). Mitchell 1976, p. 82, está de acuerdo con Galinsky en dicho punto. Por su parte, Moyaers hace notar: "Selon Bendinelli, l'artisan étrusque n'est pas le créateur du modèle. Si la thèse soutenue par Bendinelli et approuvée par Alfóldi est exacte, ces statuettes perdent de leur originalité et l'apport étrusque est minime: l'artiste a miniaturisé et adapté à la terre cuite le modèle fourni par une statue grecque se trouvant à Véies pour en tirer des ex-voto, expressions d'un sentiment dont il est difficile de saisir la nature exacte, mais que l'on ne peut assimiler aux manifestations d'un culte" (1977, pp.41-42). Cf. también Dury-Moyaers 1981, pp. 170-171. Poucet 1979, p. 179, considera dicha teoría de un gran original, del que se habrían hecho las copias, como fruto de la imaginación. Más allá de lo señalado por Galinsky, hoy aún encontramos en la bibliografía referencias a un culto a Eneas en Veyos. Cf., por ejemplo, Simon 2013, p. 504, y Bonamici 2011, p. 120, n. 43, quien cita la hipótesis de Colonna.

${ }^{30}$ Alföldi citado por Dury-Moyaers 1981, p. 165: “Aeneas was celebrated in some cities of Southern Etruria as their founder-hero: precisely in the cities which were in turn the overlords of Rome. [...] Vulci, where Aeneas as an ancestor was already venerated in the sixth century B.C., as his popularity, evident by the imported Attic vase paintings attests". Cf. Cornell 1975, p. 12, quien afirma que Alföldi es uno entre distintos investigadores - a los que no explicita, pero entre los que debemos incluir a Galinsky 1969- que sugiere que Eneas era considerado como héroe fundador en algunas ciudades etruscas. La base de esta hipótesis se encuentra en la prominencia que tienen las reliquias sagradas en las escenas que representaban la huida de Troya de Eneas con su familia en muchos vasos que se han encontrado en Etruria. Los elementos más importantes son el ánfora de figura roja de Múnich y un escarabeo etrusco de la colección Luynes en la Bibliothèque Nationale de París, datable, siguiendo a Pallottino, de la primera mitad del siglo v. a. C. Contra la tesis de Alföldi de que Eneas era venerado como ancestro en Vulci, a partir de vasos decorados con el motivo de la huida de Eneas, también se posiciona Moyaers 1977, p. 41, n. 100, y Dury-Moyaers 1981, pp. 167-168, quien cita en ambos casos la reseña de Pallottino al Die trojanischen Urahnen der Römer de Alföldi, donde el etruscólogo italiano ya se muestra escéptico frente a la hipótesis de un culto a Eneas en Etruria. Cf. asimismo Cornell 1999, p. 481, n. 54. Sobre el ánfora de Múnich, cf. también Horsfall 1979, pp. 40-41, y lámina IIIa, y 1987, p. 18, quien cuestiona la interpretación de Alföldi. Asimismo, Horsfall 1979, pp. 40-41, y lámina IIIb, y 1987, p. 18, sobre el escarabeo citado. Tampoco acepta la tesis de un culto a Eneas en Etruria Mitchell 1976, p. 82. En torno al mito de la Roma etrusca, cf. Cornell 1999, pp. 184-208. 
Galinsky Aeneas, Sicily, and Rome publicado en 1969.31 Ahora bien, esta tesis, que tuvo un importante defensor en F. Bömer ya en 1951 en su Rom und Troia, ha recibido varias críticas desde aquellos años. ${ }^{32}$ No es este el lugar para detallar tales observaciones, no obstante es interesante recalcar que la hipótesis del culto a Eneas en Etruria es rechazada rotundamente por los investigadores que la critican. ${ }^{33}$ De todos modos, la popularidad de la leyenda de Eneas en la zona sur de Etruria entre Vulci y Roma es una cuestión que pone de manifiesto la arqueología y que ningún investigador niega. ${ }^{34}$ Los hallazgos proporcionados por las excavaciones indican que con seguridad la leyenda de Eneas habría sido conocida en Etruria avanzada la segunda mitad del siglo VI a. C. y que

${ }^{31} \mathrm{El}$ autor estadounidense conjetura, siguiendo a Bömer, que la leyenda de Eneas habría pasado a Etruria en el período anterior al enfrentamiento de los foceos con los cartagineses y etruscos en 540 a. C. (Galinsky 1969, pp. 121-122). Pero se muestra en desacuerdo con la hipótesis sostenida por Schauenburg en el artículo "Aeneas und Rom", según la cual los etruscos habrían adoptado a Eneas como héroe fundador por enemistad con los griegos y, especialmente, con Odiseo (Galinsky 1969, p. 121). Sobre el culto a Eneas en Vulci afirma: "On account of the Munich amphora and the scarab (de la colección Luynes en París), on both of which the sacra of Troy are shown, we may assume, with some justification, that some south Etruscan cities, Vulci in particular, considered Aeneas as a founder-hero. The other vases with his flight testify to his popularity, although this particular representation is hardly dominant and cannot be used as evidence for the cultic ancestor worship" (Galinsky 1969, p. 131). Más adelante, Galinsky 1969, p. 139, vuelve a afirmar que hubo un culto a Eneas en Vulci. Sobre la datación del escarabeo, cf. Moyaers 1977, pp. 40-41, quien cuestiona la fecha anterior a 525 a. C. propuesta por Alföldi y Galinsky 1969, entre otros. Cf. sobre este punto también Poucet 1979, p. 180. Finalmente, cabe citar que Galinsky tampoco se muestra de acuerdo con Alföldi acerca de la existencia de un culto a Eneas en Veyos. Las estatuillas votivas de Eneas y Anquises no servirían para probar este punto en el templo de Portonaccio, ni lo haría el que en el grupo de estatuas de la acroteria del templo hubiera estado Eneas (Galinsky 1969, pp. 136, 138-139). Cf. sobre esto último la nota 29 arriba.

${ }^{32}$ Los estudios de la cuestión giran principalmente en torno al análisis de gemas, escarabeos, estatuillas, estatuas monumentales, enócoes, ánforas y otros vasos. Cf. Cornell 1975, pp. 11-12, y 1999, p. 91; Galinsky 1969, pp. 120-140; Moyaers 1977; Poucet 1979, pp. 178-181, y 1983; Dury-Moyaers 1981, pp. 165-173; Horsfall 1979, pp. 40-41, y 1987, pp. 18-19, y Gruen 1992, pp. 21-22, todos con más bibliografía.

${ }^{33}$ Cf. Cornell 1975, p. 12, n. 4; Moyaers 1977, pp. 41-42, 43; Poucet 1979, pp. 180181; Dury-Moyaers 1981, pp. 171, 172; Poucet 1983, pp. 152, 154; Horsfall 1987, p. 19 , y Gruen 1992, pp. 21-22.

${ }^{34}$ Cf., por ejemplo, Cornell 1975, pp. 5, 11-12, y 1999, p. 91; Galinsky 1969, pp. 120140; Horsfall 1987, pp. 18-19; Gruen 1992, pp. 21-22. 
tuvo cierto éxito durante varias décadas, aproximadamente entre 525 y 470 a. C. ${ }^{35}$

La relación entre troyanos y veyentes también fue propuesta por I. Bitto en 1971, en su artículo "Municipium Augustum Veiens", y M. Sordi en 1989 en su libro Il mito troiano e la eredità etrusca di Roma, quienes se basan en una inscripción del año 26 d. C., en donde se lee que los centumviri de Veyos obtuvieron el permiso de reunirse en el templo de Venus en Roma, lo que se interpreta como un reconocimiento de la ascendencia troyana de Veyos. Sin embargo, A. Giardina desestima esta lectura y asevera que la conexión con el templo de la diosa se debe al nombre del liberto que figura en la inscripción, Iulius, e, inclusive, remarca aquello que nosotros ya hemos subrayado, que el origen troyano de Veyos no está atestiguado. ${ }^{36}$

Ahora bien, aunque no podamos aducir específicamente que haya existido una reivindicación por parte de Veyos u otra ciudad etrusca de

${ }^{35}$ Esa datación ha sido aceptada desde el análisis de los distintos vasos por Schauenburg en su artículo "Aeneas und Rom" publicado en 1960; cf. Galinsky 1969, pp. 122123; Moyaers 1977, pp. 40-41; Poucet 1979, p. 180, y Dury-Moyaers 1981, p. 166. Una fecha precedente para el conocimiento de la leyenda troyana en Etruria propuso Alföldi a partir de un enócoe de fines del siglo VII a. C. encontrado cerca de Cere en una tumba de Tragliatella en 1877. Alföldi encontraría en esta jarra la prueba más antigua de la creencia etrusca en su origen troyano. Allí se observa a dos hombres a caballo saliendo de un laberinto al que se denomina TRUIA. Galinsky 1969, pp. 121-122, cuestiona la asociación que se tejió con Troya y sostiene que el significado sería "lugar fortificado". El debate en torno a dicho enócoe continúa, cf. Ogilvie 1970, p. 37; Poucet 1979, pp. 179-180, y 1983, pp. 150-151, y Horsfall 1987, p. 19. Otro enócoe, uno de figuras negras procedente de Vulci y fechado a fines del s. VII a. C. (en la Bibliothèque National de París, Cabinet des Médailles, $n^{\circ} 179$ ) también ha sido asociado por varios investigadores a la leyenda de Eneas. Sin embargo, Poucet se mantiene muy dubitativo al respecto: "En fait, il faut le dire, interpréter la peinture comme une scène de l'Ilioupersos est déjà une hypothèse et dans ces conditions, y retrouver Énée et Anchise est une «hypothèse au carré»" (1983, pp. 151-152).

${ }^{36}$ Giardina afirma: "Nel 26 d. C. i centumviri di Veio convennero 'Romae in aedem Veneris Genetricis' (CIL XI $3805=I L S 6579=$ RDGE 52), nel quadro dei festeggiamenti per il liberto del divo Augusto Gaius Iulius Gelotus, benemerito della loro città... In verità la connessione sembra dovuta non già alle origini troiane di Veio (communque non attestate), ma al nome dell'illustre liberto: un Iulius, per l'appunto, cui doveva essere quanto mai gradito essere onorato anche obliquamente, con la celebrazione del suo augusto patrono, effettuata nel tempio della dea gens Iulia" (2004, pp. 111-112). Sobre la inscripción, cf. también el análisis de Gabba 1994,pp. 146-147 = 1988, p. 204. 
un origen troyano, ${ }^{37}$ tal vez, siguiendo lo expuesto por M. Sordi en su trabajo "Il paradosso etrusco: il 'diverso' nelle radici profonde di Roma e dell'Italia romana", podamos pensar que hay otra conexión posible entre los etruscos en general y los troyanos. La historiadora italiana señala que ello tiene sus raíces en los contactos de los etruscos con Asia Menor y, probablemente, en una migración de los primeros desde aquella región a Italia. Más interesante aún es que la conexión habría sido aceptada por los etruscos en los últimos siglos de la república (III-I a. C.) a través de la leyenda de Dárdano, para lo cual, Sordi aduce, disponemos de lo que nos transmite Virgilio y de unas famosas inscripciones de Túnez descubiertas a principios del s. XX, que datarían del s. I a. C. Estos últimos dos puntos son relacionados también por otros autores que sostienen la misma idea. ${ }^{38}$

Las inscripciones que aparecen en esos tres cipos de Túnez son interpretadas y fechadas en distintos momentos y esas variaciones hacen difícil que podamos tomarlas como una base firme para señalar el nexo entre etruscos y troyanos. Resumiremos algunos puntos de la discusión que nos interesan para nuestro tema. El hallazgo de dichos cipos lo realiza A. Merlin entre 1907 y 1915, quien publica el material entre 1908 y 1919 y defiende que la lengua empleada es el etrusco. Esta hipótesis es rechazada por J. Martha en 1915, pero por imperfecciones del facsímil del que dispone para su análisis, lo que es advertido recién en 1969 por J. Heurgon, quien rectifica el facsímil y pone nuevamente en vigencia la sugerencia de A. Merlin.

Luego de esta corrección, Heurgon remarca que en la inscripción hay un detalle que hace dudar de que la asociación entre el personaje

${ }^{37}$ Bonamici 2011 lo sugiere para Volterra, aunque parte de una representación de una escena de la guerra de Troya en dicha ciudad datada en el s. I a. C. Según la autora, la élite local de Volterra habría invocado una alusión a su propio pasado para establecer un lazo de hermandad troyana con Roma en el contexto ideológico de la dinastía Julio-Claudia. Bonamici alude a la Eneida, a las inscripciones de Túnez y al caso de Veyos, en el que parece mezclarse lo que leemos en Tito Livio con la cuestión de las estatuillas votivas de Eneas. Sobre la Eneida y las inscripciones de Túnez trataremos a continuación. El caso de la ascendencia troyana de Veyos, más allá de lo que leemos en el libro 5 de Tito Livio, ya hemos señalado que no está probada. Tampoco lo está el culto a Eneas, que la autora retoma de una hipótesis de Colonna.

${ }^{38}$ Cf. Sordi 2008, pp. 90-91, 94-95, y 1991, p. 412, n. 11; Scuderi 1978, pp. 88 y 91; Grimal 1982, p. 282, y Bonamici 2011, p. 120, quien vincula la cuestión con Volterra. Virgilio menciona el tema en A. 3.165-170, 7.205 ss. 
legendario y los etruscos se deba específicamente a estos últimos: la palabra dardanium sería una palabra latina que ha sido transcrita en caracteres etruscos. Esto lleva a Heurgon a hipotetizar que la referencia a Dárdano habría sido el fruto de una sugerencia por parte de un romano, quizás Cn. Papirio Carbón en el 82 a. C., a los etruscos romanizados, posiblemente procedentes de Clusio, que realizaron la inscripción. ${ }^{39} \mathrm{La}$ colonia en cuestión no duró mucho, pues fue destruida un año después por Pompeyo. Ahora bien, el que fuera un romano quien propuso la asociación sería más posible, afirma el etruscólogo francés, ya que en el s. II a. C. la asimilación de dárdanos y troyanos estaba presente en la poesía latina. ${ }^{40}$

Esa lectura del término dardanium es puesta en tela de juicio en 1976 por O. Carruba en su artículo "Nuova lettura dell'iscrizione etrusca dei cippi di Tunisia". Carruba corrige la interpretación de Heurgon, divide el término en Dardaniv-m, y señala que el vocablo es un adjetivo etrusco con el enclítico $-m \cdot{ }^{41}$ Esta interpretación es la que siguen autores poste-

${ }^{39}$ Heurgon 1969, p. 550: "Car ce qui frappe quand on considère, dans nos inscriptions, le mot dardanium, c'est que c'est un mot latin, senti comme tel, reproduit comme tel par le rédacteur de l'inscription, qui a pris toutes les précautions possibles pour en respecter la désinence et même, par le signe diacritique qui sonorise le $t$, pour en rendre la prononciation. Si Dardanos avait existé en étrusque à cette date, on n'aurait eu aucun scrupule à écrire son nom avec la désinence étrusque et la dentale sourde: tartane. Ici nos Étrusques procèdent comme lorsqu'on cite un terme étranger: ils le mettent pour ainsi dire entre guillemets.

On n'en sera pas surpris si l'on songe qu'il s'agissait d'Étrusques profondément romanisés, qui ne recouraient à l'étrusque que dans un sursaut de nationalisme révolté, et qu'accompagnaient des Romains comme Carbo qui peut-être leur suggéra leur nom de Dardanii”.

${ }^{40}$ Cf. ibid., pp. 550-551. En cuanto a la transposición de una leyenda latina, Briquel 1991, p. 210 se muestra en desacuerdo y sigue una hipótesis de Colonna de un artículo de 1980 acerca de que la misma habría estado enraizada localmente en Etruria: "Il est difficile de faire abstraction de Corythus, et donc d'un rapport avec Cortone" (Briquel 1991, p. 210, n. 138). Cf. también Briquel, op. cit., pp. 209, 218.

${ }^{41}$ Pittau lo resume del siguiente modo: "il linguista Onofrio Carruba ha criticato la interpretazione e traduzione prospettata dall'Heurgon di Dardanivm $=$ «dei Dardani», cioè come uguale al genitivo plurale lat. Dardanium, Dardan(i)orum, ed invece, dividendo il vocabolo in Dardaniv-m, lo ha interpretato come un aggettivo propriamente ed esclusivamente etrusco, seguito dalla congiunzione enclitica $-m$, col significato dunque «e dardanio»" (1996, p. 1667). Pittau, ibid., pp. 1667-1668, se muestra de acuerdo con esta corrección de Carruba, si bien le critica otras propuestas en las que no nos detendremos aquí. 
riores, como M. Sordi o R. Scuderi, ${ }^{42}$ no obstante la primera se muestra en desacuerdo con la datación propuesta por J. Heurgon y seguida por O. Carruba ${ }^{43}$ por dos razones: 1) el tiempo que Carbón estuvo en África fue muy breve como para fundar una colonia, dado que en el mismo año 82 a. C. fue asesinado en Sicilia por Pompeyo, y 2) el hecho de que unos etruscos usen su idioma natal apenas obtenida la ciudadanía romana resulta extraño. ${ }^{44}$ Este segundo punto lo enlaza con su tesis del Dárdano etrusco:

Ma la fedeltà degli Etruschi alla causa mariana dopo il 90 era strettamente collegata con il loro desiderio dei pieni diritti di voto e dell'esercizio pieno della cittadinanza. Il ritorno alla lingua nazionale in un' iscrizione ufficiale avrebbe suonato come un'esplicita rinuncia. Datata prima del 90, invece, l'autodefinizione di Dardani, cioè di Troiani costituiva anch'essa una rivendicazione di cittadinanza, come veri Romani. ${ }^{45}$

M. Sordi, sugiere, más bien, una datación entre el 103 y el 100 a. C., durante la colonización de África. ${ }^{46}$

Tanto en este último texto, como en su aporte de 2008, M. Sordi pareciera vincular la referencia a Dárdano por los etruscos en las inscripciones con los romanos o, mejor dicho, con el deseo de etruscos por tener buenas relaciones con Roma. En el caso de la alusión a Virgilio en 2008, la aceptación de la leyenda se entendería como precedente a la cita de la cuestión por el poeta en la Eneida. Ahora bien, la vinculación entre los cipos de Uadi Milián y la Eneida no es aceptada por todos. Ya J. Heurgon se muestra en contra de ello en 1969, cuando señala que la versión de la leyenda que contó Virgilio, si bien no es un invento de éste,

${ }^{42}$ Giardina cita el artículo de Carruba en nota, pero parece preferir la hipótesis de Heurgon (Giardina 2004, pp. 70-71, 112, n. 300).

${ }^{43}$ Seguida también por Colonna, Briquel 1991, p. 210, y Bonamici 2011, p. 120.

${ }^{44}$ Cf. Sordi 1991, pp. 411-412. Giardina siguiendo a Colonna afirma: "Si è giustamente obiettato che ben difficilmente quel piccolo gruppo di coloni che si esprimevano in lingua etrusca, dopo essere stati sconfitti in una guerra civile, si sarebbero definiti Dardanii per semplice imitazione della tradizione sulle origini troiane di Roma" (2004, p. 71).

${ }^{45}$ Cf. Sordi 1991, p. 412, n. 11.

${ }^{46}$ Cf. ibid., p. 412. Al respecto de esta datación, M. Bonamici afirma: "Difficilmente sostenibile per ragioni inerenti alle caratteristiche paleografiche..." (2011, p. 120, n. 43). 
es posterior a Varrón. ${ }^{47}$ A. Giardina va más allá incluso en su desacuerdo con la tesis de M. Sordi -y R. Scuderi, entre otros - y precisa que el Dárdano virgiliano no es etrusco. El historiador siciliano señala que para Virgilio los etruscos son de origen lidio y que la llegada de aquéllos, si bien es posterior a la partida de Dárdano, es anterior al arribo a Italia de los troyanos. ${ }^{48}$

En el caso de Tito Livio, aunque éste no hace referencia a Dárdano en ningún pasaje de los libros que nos han sido transmitidos, sí podemos notar en el libro I que a la llegada de Anténor y Eneas a Italia, los etruscos ya estaban allí. ${ }^{49}$ Teniendo en cuenta este punto y lo que hemos señalado acerca del origen asiático de los etruscos - lo cual estaría implícito en la Historia de Roma desde su fundación - podemos pensar que Tito Livio, en caso de conocer la leyenda de Corito, tampoco atribuiría un origen troyano a los etruscos a partir de ella.

En 1996, M. Pittau vuelve a estudiar los cipos de Túnez, aunque considerándolos junto con otras fuentes en el contexto de las relaciones de etruscos con cartagineses..$^{50}$ El lingüista italiano acepta la interpretación propuesta por O. Carruba y, asimismo, la referencia que allí existiría a los dárdanos o troyanos, cuya leyenda, afirma, muy posiblemente habría llegado a Etruria antes que a Roma. Cita para ello la presencia de los nombres de Eneas y Anquises grabados en espejos y las famosas estatui-

${ }^{47}$ Cf. Heurgon 1969, p. 550. Cf. también Giardina 2004, pp. 70-72.

${ }^{48}$ Giardina 2004, pp. 71-72: "In realtà, malgrado le apparenze e la convinzione diffusa tra gli studiosi, il Dardano virgiliano non è un Dardano che possa essere definito, a rigor di termini, etrusco. Il sistema virgiliano esclude anzi con sufficiente chiarezza qualsiasi filiazione degli Etruschi da Dardano. Gli Etruschi sono infatti immaginati da Virgilio come provenienti dalla Lidia in una fase precedente la guerra di Troia ma successiva alla partenza di Dardano da Corythus; e come Dardano non è, a rigor di termini, etrusco, così la sua Corythus non è, a rigor di termini, etrusca. Gli Etruschi dell'Eneide non sono autoctoni e non discendono da Dardano: quando Enea li scopre essi hanno un'identità ben delineata, ed è un'identità (anche se precocemente intrisa di italicità) diversa da quella dei Troiani”. Para la crítica expresa a Sordi y Scuderi, entre otros, cf. Giardina, op. cit., p. 113, n. 304.

${ }^{49}$ La primera mención a los etruscos es la que hace Tito Livio al introducir a Mecencio, de quien nos dice que era rey de Cere, una ciudad que por aquel entonces era opulenta (1.2.3).

${ }^{50}$ Sobre este tema a partir de fuentes arqueológicas que van del s. VIII a. C. al período helenístico, cf. Gran-Aymerich 2009. Cabe señalar que este autor mantiene la datación de la república romana de los cipos a diferencia de la propuesta de Pittau, como veremos a continuación. 
llas votivas de Veyos, así como aportes de A. Alföldi y F. Zevi. A partir de todo ello, asevera que el vocablo dardanio habría llegado a Etruria directamente de los griegos y no por intermedio de los romanos. ${ }^{51}$

Un punto interesante del artículo de M. Pittau es que no acepta la fecha que O. Carruba retoma de J. Heurgon, ${ }^{52}$ ni, vale aclarar, la propuesta de M. Sordi, a quien no menciona en el trabajo. Pittau afirma que las inscripciones corresponderían a los treinta años que van del 295 al 264 a. C. El sabio italiano señala que el tipo de letra que se emplea en la misma no debe tomarse como un estilo arcaizante del s. I a. C. como ve Heurgon, sino que debe aceptarse como prueba de la época en que fue realizada la inscripción. Asimismo, cuestiona el punto de que una inscripción de los años 82-81 a. C. pudiera ser escrita en etrusco y no en latín, lo que bien podría haber significado un homenaje a Cn. Papirio Carbón que guio a los exiliados al África. Agrega, además, que si se consideran los posibles referentes, población númida, los cartagineses que pudieran haber quedado o romanos, éstos no entenderían el mensaje. M. Pittau propone, más bien, un período en que Cartago era aún poderosa y tenía buenas relaciones con Etruria, es decir el período anterior a la primera guerra púnica. ${ }^{53}$ Eso permitiría comprender que M. Unata, etrusco de Clusio, hubiera podido tener una posesión tan grande en el norte de África, lo que habría sido imposible en el período del s. I a. C. durante el enfrentamiento entre populares y optimates. En el caso del s. III a. C. el poder cartaginés habría servido de defensa incluso ante posibles ataques de nativos númidas. Finalmente, la posible migración de este etrusco a África, aclara M. Pittau, podría relacionarse con los problemas militares, políticos y sociales que asolaron Etruria en esos años. ${ }^{54}$

La propuesta de M. Pittau resulta interesante, puesto que el investigador no presenta una vinculación con la Eneida, esto la exime de las objeciones mencionadas arriba, y su hipótesis afirma una procedencia etrusca de la leyenda, que habría sido tomada de los griegos de forma

${ }^{51}$ Cf. Pittau 1996, p. 1669.

$52 \mathrm{Cf}$. idem.

${ }^{53}$ Pittau, ibid., p. 1671: "Nella supposizione invece che l'iscrizione sia molto più antica e che risalga al periodo della potenza di Cartagine, i referenti sicuri di quella epigrafe erano sia gli altri Etruschi che frequentavano l'Africa per motivi di commercio od anche di milizia mercenaria, si gli stessi Cartaginesi, buoni amici degli Etruschi in generale e non pochi perfino conoscitori della lingua etrusca".

${ }^{54}$ Cf. Pittau, op. cit., pp. 1670-1672. 
directa. Ahora bien, estos cipos serían la única evidencia al respecto, ${ }^{55}$ y su datación aún no está probada por completo. Las alusiones a la tesis de Alföldi, ya vimos, no representan una base firme y la existencia de referencias a Eneas y Anquises en Etruria no prueban, necesariamente, la existencia de la leyenda de Dárdano allí tan antiguamente. ${ }^{56}$

De nuestro resumen podemos sacar en limpio que hoy por hoy no disponemos de fuentes que nos lleven a pensar con cierto grado de certeza que haya existido una reivindicación por parte de los veyentes o de algún otro pueblo etrusco en particular de un origen troyano. ¿Hemos de extraer como consecuencia a partir de allí, como enfatizan algunos autores, que la razón de la alusión es sobre todo, por no decir meramente, literaria? ${ }^{57} \mathrm{O}$, tal vez, ¿aceptar la posibilidad de que Tito Livio haya realizado la vinculación simplemente a partir de la idea del origen lidio de los etruscos? Aunque el aspecto literario tuvo de seguro su peso en la cuestión, consideramos que no necesariamente debe recaer en él todo el peso de la causa, puesto que, si bien no hay pruebas firmes para sostener que Eneas u otro héroe troyano fuera reconocido como fundador de alguna ciudad en Etruria, las fuentes arqueológicas muestran que Eneas sí fue una figura muy popular entre los etruscos a finales del siglo VI a. C. y posteriormente. ${ }^{58}$ Con mayor exactitud, incluso, entre los etruscos

55 Pittau 1996 no aduce otra.

${ }^{56}$ Perret, veinte años antes del trabajo de Pittau, se plantea la duda sobre si en el s. V a. C. la leyenda de Dárdano ya circulaba por la ciudad pelásgica de Cortona (cf. Perret 1976, p. 800).

${ }^{57}$ Cf., por ejemplo, Ogilvie 1970, p. 628, y Kraus 1994, también parece ser la idea de Cornell 1999, p. 361.

${ }^{58}$ Más allá de la relevancia que estamos poniendo en este trabajo sobre la figura de Eneas, hay que tener presente las oportunas observaciones de Dury-Moyaers y reconocer dos cosas: 1) Eneas no es el único héroe griego cuya leyenda gozó de popularidad en Etruria, incluso había otros héroes más familiares entre los etruscos; 2) la importancia de preguntarse ¿por qué llegó la leyenda de Eneas a Etruria, si por una decisión de los griegos que la exportaron o si se debió al gusto de los compradores etruscos?; y, vinculado a esto último, 3) ¿cuánto sabían del mito griego de Eneas los etruscos que compraron esos vasos? Sobre el primer punto, cf. Moyaers 1977, pp. 39-40, 43; Dury-Moyaers 1981, pp. 165-166, y Mitchell 1976, p. 82. Sobre lo segundo, afirma Dury-Moyaers: "Schauenburg en a conclu que les Athéniens exportaient en Etrurie des vases illustrant le départ d'Enée parce que c'était un thème très prisé par les Etrusques. A notre avis, les Etrusques n'ont pu apprécier ce motif avant le moment où il leur a été proposé par les Grecs. Soucieux de fournir à leurs clients des vases répondant à leurs goûts, les ateliers céramiques ont vu dans la légende d'Enée partant pour l'Italie un sujet susceptible d'intéresser leur clientèle 
del sur, en la zona que encontramos entre Vulci y Roma, que coincide en gran parte, al menos, con la región dominada por veyentes y sus aliados, quienes se destacan en la obra de Tito Livio por ser tenaces enemigos de los romanos y que D. Musti mostró que son presentados negativamente por el historiador romano, quien, a diferencia de Dionisio de Halicarnaso, podemos considerar como un filoetrusco. ${ }^{59}$

A partir de allí, basándonos en la evidencia que ofrece la arqueología, bien podemos suponer que, en el período en que redacta su obra Tito Livio o las fuentes de éste, ${ }^{60}$ existía material suficiente para que el historiador paduano, alguna o algunas de sus fuentes realizaran la conexión entre Troya y Veyos al momento de narrar el episodio del sitio romano de esta última. ${ }^{61}$ Incluso, si consideramos la cuestión desde el período en que escribe Tito Livio su obra, podemos tener en cuenta la existencia

étrusque. L'initiative et l'impulsion viennent donc de Grèce. Les Etrusques ne pouvaient connaître Enée avant que les Grecs ne leur aient présenté le personnage” (1981, p. 167). Cf. también Gruen 1992, pp. 21-22. Sobre la tercera cuestión, vale citar lo que asevera Moyaers: "Les Etrusques recherchent avant tout l'effet esthétique et décoratif. Le même sujet peut être abordé de façon divergente selon la personnalité de l'artiste. Cette variété dans le traitement d'un même thème laisse supposer qu'aucune tradition littéraire étrusque ne sous-tend ces adaptations artistiques. Sans doute Enée n'était-il pas inconnu des Etrusques, mais il faut se garder de croire qu'ils avaient une connaissance profonde du personnage et de son mythe; dès lors, il serait audacieux de songer à un culte du héros. La tradition iconographique d'un mythe grec en Etrurie ne comporte pas la pénétration du mythe lui-même, les artisans étrusques ignorent souvent le contenu historico-religieux des légendes. Les Etrusques ont pu apprécier ce héros, sans être parfaitement au courant de ses aventures et de son contenu mythique" (1977, p. 42). Cf., asimismo, Moyaers 1977, pp. 41, 41-42; Dury-Moyaers 1981, pp. 171-72, y Poucet 1983, p. 252.

${ }^{59}$ Cf. Musti 1970. Para una postura diferente, cf. Bittarello 2009, a nuestro juicio con muchas inexactitudes.

${ }^{60}$ Dado que no se han conservado fuentes literarias etruscas y, dada la forma de citar las fuentes en la historiografía romana, es muy difícil establecer el posible uso por Tito Livio de alguna fuente etrusca que pudiera haber empleado el paralelo o haber trazado alguno entre una ciudad de esta región con Troya antes de la propaganda romana del s. I a. C. De todos modos, no debemos rechazar de plano dicha posibilidad. Sobre el probable uso o no de material etrusco por Tito Livio, cf. Bayet 1964, pp. 125-134; Phillips 1982, p. 1021, y Ferri 2010, p. 61, los dos últimos con más bibliografía.

${ }^{61}$ No es nuestro interés aquí detenernos en la discusión acerca de la procedencia de la leyenda troyana de Roma, ni en una posible idea de syngheneía entre veyentes y romanos. Para lo primero consultar los trabajos citados de Galinsky, Cornell, Moyaers, DuryMoyaers, Poucet, Horsfall, Gruen y Giardina, todos con más bibliografía; en torno a lo segundo, cf. Giardina 2004, pp. 69-70, con más bibliografía. 
de, al menos, seis estatuillas votivas de Eneas llevando a Anquises encontradas en Veyos. La datación de las mismas es difícil de establecer. Algunos estudiosos se decantan por los siglos VI o v a. C., mientras que otros consideran más probable una fecha más tardía, s. IV o, quizás, III a. C., es decir en la época en que la ciudad etrusca se encontraba ya bajo dominación romana. ${ }^{62}$ En ambos casos, estaríamos lejanos al período en que Tito Livio escribió su obra. ${ }^{63}$

Si bien, la asimilación entre el sitio de Veyos y el de Troya puede tomarse como una instancia más de adaptación a la historia romana de un motivo griego, de todos modos no consideramos que se tenga que poner más énfasis en la tradición literaria grecolatina para explicarlo que en aquello que muestra la arqueología sobre la presencia de motivos de la guerra de Troya en la región de Etruria implicada en los asuntos que narra Tito Livio. ${ }^{64}$ En ese sentido, retomamos, aunque con cautela, una apreciación de G. K. Galinsky:

${ }^{62}$ Sobre la datación de las estatuillas, cf. Gagé 1950, pp. 73-74; Hubaux 1958, p. 201; Bayet 1964, pp. 133-134; Galinsky 1969, pp. 133-134; Moyaers 1977, pp. 41-42; DuryMoyaers 1981, pp. 169-170; Poucet 1979, p. 179; Horsfall 1987, p. 18; Gruen 1992, pp. 21-22; Bonamici 2011, p. 120, n. 43; Perret 1959, pp. 127-128; Torelli 1996, p. 216, y Briquel 1990, pp. 280-281, los tres últimos son defensores de la datación baja, que minaría la tesis de una primacía etrusca de la leyenda en Italia.

${ }^{63}$ Otro aspecto interesante para nuestro análisis es la interpretación de Ferri 1954 de una estatua femenina con un niño de la acroteria del templo del Apolo de Portonaccio, apenas afuera de Veyos, como Creúsa y Ascanio huyendo de Troya; identificación sugerida anteriormente por Fuhrmann en 1941. Esta identificación hipotética junto con la asimismo hipotética existencia de una estatua de Eneas y Anquises hecha por un escultor helénico (propuesta por Bendinelli en 1948) de la que se habrían realizado copias - las estatuillas votivas - , fue seguida por Alföldi (cf. n. 29 arriba), quien sugirió que en la acroteria del templo de Portonaccio se representaba a Eneas y los suyos. La tesis de Ferri ya ha sido desestimada, cf. Hubaux 1958, pp. 259-260; Galinsky 1969, pp. 135-136; Cornell 1975, p. 11; Dury-Moyaers 1981, p. 170, y Horsfall 1987, p. 18. Para un análisis más reciente del conjunto de las estatuas de la acroteria, cf. Neils 2008. Se desconoce a qué dios, diosa o dioses estaría dedicado el templo. Para resúmenes de las posiciones sugeridas al respecto, cf. Rebuffat-Emmanuel 1961, Neils 2008, pp. 38-39. Sobre el hallazgo de la estatua femenina en cuestión, su postura, la descripción del conjunto y la ubicación, cf. Neils, ibid., p. 37, con más bibliografía. La acroteria del santuario de Portonaccio data de fines del s. VI a. C., pero éste habría conocido una fase anterior (aprox. 600 a 540 o 530 a. C.), de la cual se conservan inscripciones votivas que muestran su importancia desde entonces (Briquel 2009, pp. 43-67).

${ }^{64}$ Así, afirma Ogilvie: "Although familiarity with the Trojan history is presumed from the statuettes of Aeneas and Anchises to have been current in Veii, the assimilation of 
The familiarity with Trojan history that was current at Veii left its mark on Roman literature. It is likely to have inspired the intensive parallelism which is found in Livy's account (5.1-25) between the siege of Veii and the siege of Troy and, in this instance, provided a real, historical starting point for one of the Hellenizing adaptations in Roman historiography ${ }^{65}$

the siege of Veii with the siege of Troy is of a piece with other hellenizing adaptations in Roman history - Tarquinius Superbus or the Fabii at Cremera - and belongs to the first generation of Roman historians who were writing with an eye to a Greek audience" (1970, p. 628). Aunque lo que señala Ogilvie es muy probable, no disponemos de ninguna fuente de Tito Livio que haya realizado explícitamente la conexión entre Veyos y Troya. Es más, la fuente más temprana de las que disponemos que narra los hechos es Tito Livio. Así, notamos que Diodoro Sículo habla de 11 años que habría durado el sitio (14.93.2) y, con posterioridad a Tito Livio, la versión de Plutarco no tiene referencias a Troya ( $\mathrm{Cam}$. 2-7). En ese sentido, atribuir a un autor precedente la relación resultaría, quizás, menos adecuado que atribuirla a Tito Livio, cuya obra tenemos. Al fin de cuentas, ya sea que él haga la asimilación, ya que él la haga explícita o ya que la mantenga tal como la encuentra en sus fuentes, lo que nos interesa es ver cómo existía una posibilidad fuera de la literatura para que esa asimilación resultara posible.

${ }^{65}$ Cf. Galinsky 1969, p. 137. Inmediatamente a continuación, Galinsky agrega: "It should be noted that it is the Romans who are cast in the role of the victorious Greeks, whereas the Trojan Veientines are their conquered enemies. This indicates that in the first part of the fourth century the Romans had not yet come to consider themselves as Trojans" (1969, p. 137). Esta parte es más confusa para nosotros. Plantear a partir de elementos anteriores a Tito Livio una hipótesis que nos ayude a comprender la existencia de ciertos elementos en su obra es, a nuestro juicio, válido, pero emplear la obra de dicho historiador con el objetivo de negar la existencia de una propaganda para un período tan distante de su escrito, resulta más difícil de aceptar. Sobre todo, si tenemos en cuenta lo complejo que es lidiar con material de historia de Roma anterior al s. III a. C. Cf. acerca de esto último Richardson 2012, quien, cabe señalar, ofrece una postura un tanto extrema al respecto. Cf. Moreno 2014. Para otras observaciones al análisis más amplio que propone Galinsky 1969 ver arriba. Más allá de ellas, consideramos válido retomar lo dicho por el autor norteamericano en cuanto a esta asociación de Veyos, a la que no relaciona con un culto a Eneas, y Troya en la narración de Tito Livio de la caída de esta ciudad etrusca, puesto que, si omitimos lo que citamos en esta nota al pie, nos parece más ajustada que lo que encontramos en investigaciones posteriores. No he podido consultar el trabajo de Ferri "Vei patria victa", publicado en Hommages à L. Herrmann en 1960. Sólo he leído el resumen que ofrece Phillips: "S. Ferri suggests that the deliberate associations made between the siege and capture of Troy and the siege and capture of Veii in the first part of Book 5 may be a literary survival of a real ethnic connection between the populations of Rome and Veii and of their shared belief in a goddess and ritual that went back to Anatolian antecedents. Camillus' scrupulous attention to religious matters at the time of Veii's fall would then be explained by the need to soothe any possible resentment among that part of the plebs which had family ties with Veii" (1982, p. 1009). 


\section{Conclusión}

Retomando el artículo de C. S. Kraus, último trabajo que se detuvo a considerar el paralelo entre el asedio de Veyos y el de Troya en el libro 5 de la Historia de Roma desde su fundación, nuestra investigación siguió un camino que ahondó en las cuestiones externas a la narración de Tito Livio, aspecto que fue dejado de lado por la autora para este caso particular y que parece haber perdido terreno en varios de los últimos análisis de dicha obra en general. ${ }^{66}$ De todos modos, no es nuestra postura la de negar los aportes de la aproximación más literaria aquí, principalmente, puesto que el propio autor de la fuente explicita el paralelo. Es por ello que, a fin de reconocer la importancia de aquellas contribuciones, dedicamos la primera parte a resumir las alusiones que, con mayor o menor grado de posibilidad, han sido sugeridas como implícitamente presentes en la narración.

La segunda parte de este estudio se detuvo en diferentes hipótesis que se han defendido en torno al posible nexo de troyanos con veyentes o con etruscos en general. Allí, pudimos observar, tal como el epígrafe de J. Perret nos apeló a reflexionar, la dificultad que tenemos para determinar con cierta seguridad distintos aspectos asociados a la leyenda troyana en Etruria, especialmente el origen. Nuestro repaso por los avances investigativos sobre la temática arroja como resultado que no hay evidencia firme en la cual basar una tesis indiscutible de un culto a Eneas en Veyos u otra ciudad etrusca. La bibliografía parece fluctuante al respecto y uno se termina preguntando hasta qué punto la defensa de la existencia de tal culto, al menos en Veyos, no depende de la subjetividad de cada estudioso al momento de interpretar los pocos datos disponibles. Incluso, en caso de aceptar dicho culto, pareciera que el mismo dataría del período de dominación romana.

Tampoco la reivindicación de una ascendencia troyana por parte de veyentes en particular o etruscos en general es una cuestión que podamos asegurar a partir de las fuentes que tenemos, más allá del énfasis que algunos especialistas quieran hacer con base en la interpretación de material de los siglos I a. C. y I d. C. La inscripción del año 26 d. C.

\footnotetext{
${ }^{66}$ Sobre esta aproximación literaria en la historiografía latina, cf. mi artículo "La moral en la interpretación del pasado en la historiografía latina", en Anales de la Escuela de Historia Virtual, en prensa.
} 
perteneciente al Municipium Augustum Veiens no permite una lectura en favor del origen troyano de Veyos, sino que, como sostiene A. Giardina, debemos reconocer allí una vinculación con la familia Iulia.

El caso de los cipos de Túnez tampoco ofrece una solución clara. Más allá de la sugerencia propuesta por M. Pittau quien retrocede la fecha de los mismos hasta el primer tercio del s. III a. C., la mayoría de los analistas prefieren una datación del s. I a. C. La alusión a Dárdano no parece tampoco un elemento tan claro para afirmar la reivindicación por parte de los propios etruscos de una ascendencia troyana. La referencia al Dárdano virgiliano, como hemos visto, no sirve para cimentar este punto.

De todas formas, los resultados de nuestro estudio no nos llevan nuevamente a la postura que leemos en C. S. Kraus o en R. M. Ogilvie, las fuentes arqueológicas evidencian que la figura de Eneas gozó de popularidad entre el 525 y el 470 a. C. en la zona de Etruria que se extiende entre Vulci y Roma. Este dato bien puede asociarse con la particular caracterización negativa que los etruscos de esa región tienen en la obra de Tito Livio, un autor que, como D. Musti resaltó, muestra una visión filoetrusca. Quizás, también la teoría del origen asiático de los etruscos, un elemento que no debemos reducir meramente a una cuestión literaria, haya jugado su papel en la cimentación de la asociación entre troyanos y etruscos en el episodio analizado.

Con esto, queremos subrayar una vez más, no proponemos desconocer la importancia de los motivos literarios, sino, más bien, plantear la importancia de no limitarnos a ellos en nuestra reflexión sobre la cuestión. Eso llevaría a perder de vista la riqueza del contexto en el que Tito Livio escribió su obra.

En síntesis, a partir de lo que hemos estudiado, podemos considerar que, si bien la idea del origen oriental de los etruscos podría ser un aspecto que posibilita la relación entre Veyos y Troya, lo que ofrece la arqueología hasta el momento nos permite pensar también en que la popularidad de la figura de Eneas en la región sur de Etruria podría ser un factor que dio pie a dicha relación, que se resalta a través de las alusiones literarias. ${ }^{67}$

${ }^{67}$ De nuevo quisiera recordar, como lo marcamos en la nota 60 , la importancia de no negar un aspecto como pudo ser la incidencia de una fuente literaria etrusca, aunque por el momento no contemos con pruebas al respecto. 
A partir de allí y retomando la frase de Ogilvie que hemos citado como epígrafe al comienzo, cabe afirmar que el recuerdo del poder que tuvo Veyos, de la encarnizada lucha que entabló contra ella Roma para controlar ciertas rutas comerciales y el acceso a los yacimientos de sal, la hizo merecedora de que su derrota final deviniera en un triunfo legendario para los romanos. Un triunfo sólo comparable posteriormente por las razones y por la dimensión del enemigo en relación con la dimensión de Roma en cada contexto, con el triunfo sobre Cartago. ${ }^{6}$

\section{BIBLIOGRAFÍA}

\section{Fuentes}

Tite-Live, Histoire Romaine, t. V, livre V, $2^{\mathrm{e}}$ éd., texte établi par J. Bayet et traduit par G. Baillet, Paris, Les Belles Lettres, 1964 [1954'] (Collection des Universités de France, Guillaume Budé).

Tito Livio, Historia de Roma desde su fundación, t. II, libros IV-VII, traducción y notas de J. A. Villar Vidal, Madrid, Gredos, 2001.

\section{Bibliografía especializada}

Adams Holland, L., "Review of J. Hubaux, Rome et Véies", AJP, 80/1, 1959, pp. 447-449.

Bittarello, M. B., "The Construction of Etruscan 'Otherness' in Latin Literature”, $G \& R, 56 / 2,2009$, pp. 211-233.

BonAmici, M., "Un programma figurativo troiano a Volterra nel i sec. a. C.", en D. F. Maras (a cura di), Corollari. Scritti di antichità etrusche e italiche in omaggio all'opera di Giovanni Colonna, Pisa-Roma, Fabrizio Serra Editore, 2011, pp. 111-120.

BRiQuel, D., "L'autochtonie des étrusques chez Denys d'Halicarnasse", Rev. Ét. Lat., 61, 1983, pp. 65-88.

BRIQuel, D., "Visions étrusques de l'autochtonie", DHA, 12, 1986, pp. 295-313.

Briquel, D., "Sordi (Maria), Il mito troiano e l'eredità etrusca di Roma", Rev. Ét. Grec., 103/490-491, 1990, pp. 280-281.

${ }^{68}$ Incluso, parece que se pueden detectar varios pasajes donde la referencia a los sucesos de la guerra contra Cartago son identificables. Cf., por ejemplo, Ogilvie 1970, pp. 660-661, 670-671, 674-675, 677, 678-679, 741-742, y Ferri 2010, p. 40, n. 68, pp. 43, 65, $67,81,86,87-88$. 
BRIQUEL, D., L'origine Lydienne des Étrusques. Histoire de la doctrine dans l'Antiquité, Rome, École Française de Rome, 1991 (Publications de l'École Française de Rome, 139).

Briquel, D., "Les Inscriptions Votives du Sanctuaire de Portonaccio à Véies", en M. Gleba y H. Becker (eds.), Votives, Places and Rituals in Etruscan Religion. Studies in honor of Jean MacIntosh Tufa, Leiden, Brill, 2009, pp. 43-67.

BRIQUEL, D., "Etruscan origins and the Ancient Authors", en J. M. Turfa (ed.), The Etruscan World, London-New York, Routledge, 2013, pp. 36-55.

CoRnell, T. J., "Aeneas and the twins: the development of the Roman foundation legend", Proceedings of the Cambridge Philological Society, 21, 1975, pp. $1-32$.

Cornell, T. J., Los orígenes de Roma c. 1000-264 a. C. Italia y Roma de la Edad del Bronce a las guerras púnicas, Barcelona, Crítica, 1999 [1995¹].

Dury-Moyaers, G., Énée et Lavinium. A propos des découvertes archéologiques récentes, Bruxelles, Latomus, 1981.

FERRI, G., Tutela urbis. Il significato e la concezione della divinità tutelare cittadina nella religione romana, Stuttgart, Franz Steiner Verlag, 2010.

FERRI, S., “«Divinatio in fastigium Veiens»”, SCO, 11, 1954, pp. 524-529.

GabBA, E., "Municipium Augustum Veiens", en Italia Romana, Como, Biblioteca di Athenaeum/Edizioni New Press, 1994, pp. 145-147 (Biblioteca di Athenaeum, 25) [= "Municipium Augustum Veiens", Athenaeum, 66, 1988, pp. 203-204].

GaGé, J., Huit recherches sur les origines italiques et romaines, Paris, Éditeur E. de Boccard, 1950.

GaGé, J., “Alpanu, la Némésis étrusque, et l' «Extispicium» du siège de Véies”, Mélanges d'archéologie et d'histoire, 66, 1954, pp. 39-78.

Galinsky, G. K., Aeneas, Sicily, and Rome, Princeton, Princeton University Press, 1969.

GiardinA, A., L'Italia romana. Storie di un'identità incompiuta, Bari, Editori Laterza, $2004\left[1997^{1}\right]$.

GRAN-AYMERICH, “'Gli Etruschi fuori d'Etruria': Dons et Offrandes Étrusques en Méditerranée Occidentale et dans l'Ouest de l'Europe", en M. Gleba y H. Becker (eds.), Votives, Places and Rituals in Etruscan Religion. Studies in Honor of Jean MacIntosh Turfa, Leiden, Brill, 2009, pp. 15-41.

Grimal, P., "Le retour des Dardanides, Une légitimité pour Rome”, Journ. Sav., 1982, pp. 267-282.

GruEN, E. S., Culture and National Identity in Republican Rome, Ithaca, New York, Cornell University Press, 1992.

Hall, E., Inventing the Barbarian. Greek Self-Definition through Tragedy, Oxford, Clarendon Press, 1989.

Hartog, F., Memoria de Ulises. Relatos sobre la frontera en la antigua Grecia, Buenos Aires, Fondo de Cultura Económica, 1999 [1996¹].

Heurgon, J., "Inscriptions étrusques de Tunisie", Comptes rendus des séances de l'Académie des Inscriptions et Belles-Lettres, 113/4, 1969, pp. 526-551. 
Horsfall, N., "Stesichorus at Bovillae?”, JHS, 99, 1979, pp. 26-48.

Horsfall, N., "The Aeneas-legend from Homer to Virgil", en J. N. Bremmer y N. Horsfall (eds.), Roman Myth and Mythography, London, University of London, Institute of Classical Studies, 1987 (Bulletin Supplement S. no. 52), pp. 12-24.

Hubaux, J., Rome et Véies. Recherches sur la chronologie légendaire du moyen âge romain, avec la collaboration de J. Hubaux, Paris, Les Belles Lettres, 1958.

Kraus, C. S., "No second Troy': Topoi and refoundation in Livy, Book V", TAPhA, 124, 1994, pp. 267-289.

Levene, D. S., Religion in Livy, Leiden-New York-Köln, E. J. Brill, 1993.

Levene, D. S., Livy on the Hannibalic War, Oxford, Oxford University Press, 2010.

Mitchell, R. E., "Roman Coins as Historical Evidence: The Trojan Legends of Rome", ICS, 1, 1976, pp. 65-85.

Moreno, A., "Reseña de James H. Richardson: The Fabii and the Gauls. Studies in historical thought and historiography in Republican Rome (Historia Einzelschriften 222, Stuttgart, Franz Steiner Verlag, 2012)", Anuario de la Escuela de Historia Virtual, 5/6, 2014, pp. 188-192 (en formato digital. ISSN: 1853-7049). Disponible en: <http://publicaciones.ffyh.unc.edu.ar/index.php/anuariohistoria/ article/view/1401/1270>.

Moreno, A., "La moral en la interpretación del pasado en la historiografía latina", Anuario de la Escuela de Historia Virtual, 11, en prensa.

MoyAERS, G., "Énée et Lavinium. A la lumière des découvertes archéologiques récentes", $R B P h, 55 / 1,1977$, pp. 21-50.

Musti, D., "Tendenze nella storiografia romana e greca su Roma arcaica: studi su Livio e Dionigi d'Alicarnasso", QUCC, 10, 1970, pp. 3-159.

NeILS, J., "Niobe (?) on the Portonaccio Temple at Veii", EtrStud., 11, 2008, pp. 35-48.

Niebuhr, B. G., The History of Rome, vol. II, Cambridge, Editorial, 1832 [1830ㄹ].

OAKLeY, S. P., A commentary on Livy. Books VI-X. Volume I: Introduction and Book VI, Oxford, Oxford University Press, 2004 [1997¹].

Ogilvie, R. M., A Commentary on Livy. Books 1-5, Oxford, Clarendon Press, 1970 $\left[1965^{1}\right]$.

Paul, G. M., "Urbs Capta: sketch of an ancient literary motif”, Phoenix, 36/2, 1982, pp. 144-155.

Perret, J., "Comptes rendus: J. Hubaux, Rome et Véies. Recherches sur la chronologie légendaire du moyen âge romain", RBPh, 37/1, 1959, pp. 125-127.

PERret, J., “Athènes et les légendes Troyennes d'Occident”, en L'Italie préromaine et la Rome républicaine. Mélanges offerts à Jacques Heurgon, Rome, École Française de Rome, 1976 (Publications de l'École Française de Rome, 27), pp. 791-803.

Phillips, J. E., “Current Research in Livy's First Decade: 1959-1979”, Aufstieg und Niedergang der römischen Welt, II.30.2, 1982, pp. 998-1057. 
PhILLIPS III, C. R., "Approaching Roman Religion: The case for Wissenschaftsgeschichte", en J. Rüpke (ed.), A Companion to Roman Religion, MaldenOxford-Victoria, Blackwell Publishing Ltd., 2007, pp. 10-28.

PitTau, M., "Gli Etruschi e Cartagine: i documenti epigrafici", en L'Africa romana: atti dell'11. Convegno di Studio, 15-18 dicembre 1994, Cartagine, Tunisia, Sassari, Editrice Il torchietto. V.3, 1996, pp. 1657-1674.

PoucET, J., "Le latium protohistorique et archaïque à la lumière des découvertes archéologiques récentes (Deuxième partie)", Ant. Class., 48/1, 1979, pp. 177220.

PoucET, J., "Énée et Lavinium. À propos d'un livre récent", $R B P h, 61 / 1,1983$, pp. 144-159.

Rebuffat-Emmanuel, D., "Contribution à l'identification des divinités de Portonaccio", Latomus, 20/3, 1961, pp. 469-484.

Richardson, J. H., The Fabii and the Gauls. Studies in historical thought and historiography in Republican Rome, Stuttgart, Franz Steiner Verlag, 2012.

Ruch, M., "La capture du devin (Tite-Live v, 15)", Rev. Ét. Lat., 44, 1966, pp. 333-350.

SChauenburg, K., "Aeneas und Rom”, Gymnasium, 67, 1960, pp. 176-191.

SCUDERI, R., "Il mito eneico in età augustea: aspetti filoetruschi e filoellenici", Aevum, 52/1, 1978, pp. 88-99.

SimON, E., "Greek myth in Etruscan culture", en J. M. Turfa (ed.), The Etruscan World, London and New York, Routledge, 2013, pp. 495-512.

SorDI, M., "La fuga di Mario nell'88 e gli Etruschi d'Africa", Klio, 73, 1991, pp. 408-412.

Sordi, M., "Il paradosso etrusco: il 'diverso' nelle radici profonde di Roma e dell'Italia romana", en G. Urso (ed.), Patria diversis gentibus una? Unità politicia e identità etniche nell'Italia antica, Atti del Convegno Internazionale Cividale del Friuli, 20-22 settembre 2007, Pisa, Edizioni ETs, 2008 (I Convegni della Fondazione Niccolò Canussio, 7), pp. 89-97.

Torelli, M., Historia de los etruscos, Barcelona, Crítica, 1996 [1981니]. 